\title{
Hormones in pain modulation and their clinical implications for pain control: a critical review
}

\author{
Xueyin Chen, Jinyuan Zhang, Xiangrui Wang \\ Department of Pain Management, Renji Hospital, School of Medicine, Shanghai Jiao Tong University, Shanghai, China
}

\begin{abstract}
Recently, more and more studies have found that pain generation, transmission and modulation are under hormonal regulation. Indeed, hormonal dysregulation is a common component of chronic pain syndromes. Studies have attempted to determine whether the relationship between the pain and its perception and hormones is a causative relationship and how these processes interrelate. This review summarizes and analyzes the current experimental data and provides an overview of the studies addressing these questions. The relationship between pain perception and endocrine effects suggests that hormones can be used as important biomarkers of chronic pain syndromes and/or be developed into therapeutic agents in the fight against pain.

Key words: Endocrine system, Central mechanism, Central sensitization pain, Hormones, Modulation, Neuropathic pain, Nociceptive pain, Peripheral effect
\end{abstract}

\section{INTRODUCTION}

Pain is defined by the International Association for the Study of Pain (IASP) as an unpleasant sensory and emotional experience associated with actual or potential tissue damage. Mechanism-based pain classification was proposed for more effective pain management. Broadly speaking, three categories of pain have been described in the literature: nociceptive pain, neuropathic pain, and central sensitization pain. Nociceptive pain is pain that is caused by tissue damage and it is usually described as a sharp, aching, or

Address for correspondence:

Dr. Xiangrui Wang, Department of Pain Management, Renji

Hospital, School of Medicine, Shanghai Jiao Tong University,

1630 Dongfang Road, Shanghai 200127, China;

Tel.: +86 21 68383198; Fax: +86 21 50903239;

E-mail: xiangrui68@163.com

Received: 09-01-2016, Accepted: 11-07-2016 throbbing pain that is proportional to the nociceptive input. ${ }^{1}$ Neuropathic pain is defined as pain caused by damage or disease affecting the somatosensory nervous system. ${ }^{2}$ Central sensitization is a condition of the nervous system whereby there is an increased neuronal response to stimuli associated with the development and maintenance of chronic pain and reduced pain modulation. ${ }^{3}$ There is a significant overlap between these three concepts and specific classification of any pain must be carried out according to the predominant type of pain presented.

Recent research has shown that the generation of pain, its transmission, and modulation are directly associated with the endocrine system including proopiomelanocortin (POMC) products, adrenocorticotrophin $(\mathrm{ACTH})$ and the endorphins, the thyroid system hormones (TRH, TSH, T3), the growth hormone $(\mathrm{GH})$, prolactin, melatonin, insulin, calcitonin, so- 
matomedin, somatostatin, histamine and vasopressin. Hormonal dysregulation is closely associated with chronic pain syndromes. A diagnostic challenge is in assessing whether these changes are a coincidence or a consequence and how they are interrelated. This review summarizes and analyzes the recent studies conducted to determine the relationship between chronic pain and hormones.

\section{ENDORPHIN AND PAIN MODULATION}

The most thoroughly studied hormones related to pain are those that belong to the endogenous opioid system. It should be noted that $\beta$-endorphin, adrenocorticotropic hormone (ACTH), and the melanocytestimulating hormones (MSH) derive from a common precursor molecule, the proopiomelanocortin (POMC). ${ }^{4,5}$ Loh et al showed in 1976 that $\beta$-endorphin had a potent analgesic effect, and indeed 18 to 33 times more potent compared to morphine on a molar basis. Additionally, they found that chronic, localized infusion of $\beta$-endorphin into the rat brain could induce morphine-like physical dependence. ${ }^{6}$ Several early studies examined the analgesic and pain modulatory effects of $\beta$-endorphin and the binding of the peptide to specific opioid receptors affecting cyclic adenosine monophosphate levels and calcium uptake. ${ }^{7}$ Most of these studies were focused on the effects of this peptide on the central nervous system.

More recently published studies have shown that the products of the POMC gene also affect the immune cells including the lymphocytes, monocytes, macrophages, granulocytes, and mast cells. This may partially explain the role that endorphin can play in the acute pain phase and the overall inflammation. After basic molecular processing, endorphin is packaged in membrane-bound secretory vesicles ${ }^{8}$ ready to be released when required. The stress of inflammation triggers the release of corticotrophin-releasing hormone (CRH). ${ }^{9}$ The endorphin-producing cells have receptors for $\mathrm{CRH}$, which then facilitate the release of endorphin. Interestingly, these immune cells also have receptors for endorphin themselves, this indicating an autocrine/paracrine effect of endorphin on the immune cells ${ }^{10}$ modulating signal transmission of inflammation, the production of cytokines, ${ }^{11}$ and its progress. ${ }^{12}$ The increased level of opioid peptides, including endorphin, in the systemic circulation during inflammation may originate from the pituitary as well as from peripheral immune cells. As has been shown by several studies, opioid receptors are widely expressed throughout the central and peripheral nervous systems and in numerous non-neuronal tissues. ${ }^{13}$ This may help explain the antinociceptive effect of endorphin on peripheral sensory terminals, a peripheral effect usually combined with several CNS effects. Elucidation of the relationships between endorphin, the immune system, and pain may enable us to find the key points to ameliorate or even inactivate the various components of inflammation triggering pain.

Opioid receptor antagonists induce hyperalgesia, ${ }^{14}$ while activation of opioid receptors provides pain relief. During the acute phase of inflammation, tissue injury-induced $\mu$-opioid receptor constitutive activity $\left(\mathrm{MOR}_{\mathrm{CA}}\right)$ can suppress spinal nociceptive signaling. ${ }^{15}$ Studies from mice and humans have confirmed endogenous opioid-masked latent pain sensitization, which provides proof of the relationship between endogenous opioids and the transition of pain from acute to chronic. ${ }^{16}$ As a cornerstone therapy for the treatment of moderate to severe pain, the use of opioids has escalated in recent years. Exogenous opioid receptor antagonists may increase sensitivity to pain or aggravate preexisting pain. ${ }^{17}$ The exact mechanisms of opioid-induced hyperalgesia are not completely understood, thus, investigation of endogenous opioids like endorphin is likely to increase our understanding of the mechanisms involved in the occurrence of hyperalgesia and the transition from acute to chronic pain.

The concentration of endogenous opioids is thought to be associated with the level of pain. ${ }^{18}$ Jadric R et al ${ }^{19}$ compared rat brain $\beta$-endorphin values after continuous treatment with different anti-depressive drugs and found that amitriptyline produced a greater response and showed higher brain $\beta$-endorphin concentration. Similarly, a study on chronic pain in humans conducted by Bruehl S showed that an elevated resting plasma $\beta$-endorphin may be a potential biomarker, indicating as it did a reduced endogenous opioid analgesic effect. ${ }^{20}$ However, more recent results do not support resting plasma $\beta$-endorphin levels as a clinically useful predictor of opioid analgesic responses. ${ }^{21}$ The 
evaluation of $\beta$-endorphin levels in body fluids might be useful as a marker for disease diagnosis and treatment, but further evidence is required.

\section{THE HYPOTHALAMIC-PITUITARY-ADRENAL (HPA) AXIS AND THE ACTH}

Grieo EN et al provided evidence for the dysregulation of the hypothalamic-pituitary-adrenal (HPA) axis in patients with fibromyalgia (FM), a disorder associated with altered functioning of the stress-response system and a classic example of central sensitization. FM is marked by mild hypocortisolemia, hyperactivity of pituitary to hypocortisolemia, hyperactivity of pituitary ACTH release to $\mathrm{CRH}$, and glucocorticoid feedback resistance. ${ }^{22}$ This phenomenon has been found in other conditions related to central sensitization and prolonged stress such as the chronic fatigue syndrome ${ }^{23}$ and irritable bowel syndrome. ${ }^{24}$ Researchers including G Blackburn-Munro came up with the "Coincidence or Consequence" hypothesis, which described chronic stress-induced HPA dysfunction as a potential common link between chronic pain and depressive illness, this conceivably explaining the prevalence of chronic pain when the CNS undergoes sensitization. ${ }^{25}$

HPA dysregulation is not clearly observed in other pain categories. EN Grieo's study also reported that hypocortisolemia was observed in nociceptive pain but found no evidence of HPA disruption. In the chronic neuropathic pain model, abnormal cortisol levels were suggested as being abnormal. However, a subsequent study based on a rodent neuropathic pain model determined that increased nociceptive sensitivity during chronic pain is associated with changes in the limbic system that were not related to HPA axis activation. This study confirmed that mRNA expression of corticotrophin-releasing hormone was increased in the central amygdala but not in the paraventricular nucleus of the hypothalamus, center of the HPA axis. ${ }^{26}$

HPA axis activation is an effective strategy adopted by the body during acute inflammatory and stress. Steroids taken orally or by injection are commonly used approaches to manage acute and chronic pain, although the outcomes are controversial. Further basic and clinical studies are necessary to elucidate the function of the HPA axis and steroids in pain management. It is important to determine their effects on the local pain generation and CNS information processing and assessing systems which may influence the rational use of glucocorticoids and optimize treatment strategies of chronic pain with regard to central sensitization.

\section{THE THYROTROPIN GROUP (TRH, TSH, T3)}

In the early nineties, rheumatologists from the Netherlands found that treatment for thyroid dysfunction resulted in a temporary effect on musculoskeletal symptoms. ${ }^{27}$ This result suggested a potential relationship between thyroid dysfunction and musculoskeletal symptoms. Since then, thyroid hormones (THs) were found to play significant roles in other chronic pain syndromes such as headache, arthritis, arthralgia, myopathies, and fibromyalgia. ${ }^{28,29}$

A recent study found that hypothyroidism during pregnancy promoted hypersensitivity to noxious thermal stimulus. ${ }^{30}$ Other studies have shown that THs are essential for the normal maturation of CNS and brain function at the anatomical, biochemical, and neurophysiological levels, ${ }^{31,32}$ and that there is a connection between thyroid hormones and pain perception. ${ }^{33}$

Based on experimental and clinical evidence, physiologists speculate that $\mathrm{THs}$ regulate pain perception by modulating the function of the Gamma-Amino-Butyric Acid (GABA) system. The GABAergic system plays an important role in nociceptive signal processing in the CNS. The GABA-A receptor mediates neural inhibition via postsynaptic action on spinal cord neurons and the cerebral cortex..$^{34}$ Once the inhibition is reduced, it contributes to the development of neuropathic pain. ${ }^{35}$ This regulation of GABA-A receptor is also related to central sensitization and may be an underlying cause of allodynia. The relationship between GABA and THs is mutual. THs affect the entire GABAergic circuit, including enzyme synthesis, metabolism, release, receptor binding, and reuptake. At the same time, GABA inhibits thyroid stimulating hormone (TSH)-stimulated TH release from the thyroid gland and TSH secretion from the pituitary. ${ }^{36}$ Additional research is required to determine the role of THs in pain production, transmission, and amplification. 
It should be noted here that several hypothalamuspituitary-thyroid (HPT)-related factors are involved in the maintenance of normal nervous system function and also in the onset of abnormal states such as chronic pain. In future clinical application, thyroid hormones will either be important biomarkers of chronic pain syndromes during the onset or maintenance phases or may be developed as therapeutic interventional tools in pain control.

\section{THE GONADAL HORMONES}

There is compelling evidence of gender differences in the epidemiology, symptomatology, pathophysiology, and treatment outcome in both clinical pain conditions and experimental studies. Fibromyalgia, ${ }^{37}$ migraine, ${ }^{38}$ functional dyspepsia, ${ }^{39}$ chronic pelvic pain,${ }^{40}$ chronic fatigue syndrome,${ }^{41}$ depression,${ }^{42}$ and irritable bowel syndrome ${ }^{43}$ are all more prevalent in females. Thus, it is reasonable to investigate the effects of gonadal hormones, especially that of estrogens, on pain pathways including pain generation, transmission, and central processing. Because female gonadal hormones fluctuate with the menstrual cycle, if estrogen contributes to pain processing, pain perception would change during the menstrual cycle. However, a review of recent well-controlled studies failed to find evidence of an effect of menstrual cycle phase on the perception of pain sensitivity. ${ }^{44}$ There is little evidence of an estrogenic influence in pain processing caused by crosstalk between the estrogen and opioid receptors through classic secondary messengers and downstream gene transcriptional regulators. ${ }^{45}$ Several studies support a role for testosterone in dampening pain and raising the pain threshold. ${ }^{46,47}$ Additional research is needed to clarify the effects of estrogen and of testosterone on pain modulation and elucidate the potential biological mechanism for such effects.

Similarly to pain perception, pain coping strategies are also different between men and women. Psychosocial mechanisms may be more fundamental than biological mechanisms. ${ }^{48} \mathrm{~A}$ study of pain-related brain activation revealed that the menstrual cycle can affect the general bodily awareness systems and modulate pain at the cognitive level. ${ }^{49}$

In terms of clinical implications, sex hormones may help in the treatment of chronic pain and tes- tosterone has been found to be effective in treating central sensitization in fibromyalgia patients. ${ }^{50} \mathrm{Ad}-$ ditional research is warranted to further elucidate the mechanisms of sex differences in pain to facilitate sex-specific treatments that consider both biological and psychological factors.

\section{MELATONIN}

Melatonin, a hormone synthesized and secreted by the pineal gland, plays an important role in the regulation of several important physiological functions including sleep and the circadian rhythm. In the early 1980 s, scientists found that information derived from environmental light exposure affected pain sensitivity via the pineal gland hormone melatonin. ${ }^{51}$ There is an increasing number of recent studies on the effects of melatonin on pain.

Melatonin has different roles in different pain states due to its widespread presence in the $\mathrm{CNS}^{52}$ and in a variety of tissues. The potent and long-lasting antinociceptive effects of melatonin during acute pain status has been reviewed. ${ }^{53}$ Experiments suggest that the analgesic effects of melatonin might be related to the opiate system. ${ }^{54}$ In 2005 , it was determined that melatonin exerted its analgesic function not by binding to opioid receptor subtypes but by increasing the release of $\beta$-endorphin, the endogenous opioid. ${ }^{55}$ In addition, a recent study found that melatonin can prevent morphine-induced hyperalgesia and tolerance by inhibiting the protein kinase $\mathrm{C}$ and N-methyl-Daspartate pathways. ${ }^{56}$

During the inflammatory pathophysiological state, activation occurs of different pharmacological targets of melatonin, including iNOS, COX-2, cytokines, and molecule productions. Its anti-inflammatory effects are driven via a number of different classic transcriptional pathways including NFאB, HIF, cAMP, STAT, and AP- $1 . .^{57}$

In the case of the neuropathic pain, melatonin was found to be effective in treating nerve injury ${ }^{58}$ spinal cord injury, ${ }^{59}$ post-herpetic neuralgia,${ }^{60}$ and migraine. ${ }^{61}$ Oxidative stress contributes to all these conditions and melatonin acts as an antioxidant, working as a free radical scavenger in the L-arginine- $\mathrm{NO}^{58}$ and $\mathrm{N}$-methyl-D-aspartate ${ }^{62}$ pathways. 
Several painful disorders have been associated with central nervous system sensitization to pain. Abnormal serum melatonin concentrations have been detected in patients with most of these syndromes, which include fibromyalgia, ${ }^{63}$ chronic fatigue syndrome, ${ }^{64}$ and irritable bowel syndrome. ${ }^{65}$ However, the causes and consequences of this phenomenon have not been elucidated. Further research is needed to determine its function in reducing central sensitization to pain.

Currently, melatonin is used as an adjuvant drug in the treatment of several specific conditions, mainly due to its ability to improve sleep. In consideration of its antinociceptive potential, it might be developed as a useful analgesic in the near future and become as common as nonsteroidal anti-inflammatory drugs (NSAIDs) or opioids.

\section{CALCITONIN}

Calcitonin (CT), discovered in 1961 by H Copp, ${ }^{66}$ is a 32 -amino acid hormone secreted by the parafollicular cells of the thyroid gland. In humans, it exerts a minor effect on calcium balance. ${ }^{67} \mathrm{CT}$ was used, and abused, as an analgesic treatment of painful conditions such as osteoporosis ${ }^{68}$ phantom limb pain, ${ }^{69}$ diabetic neuropathy, ${ }^{70}$ complex regional pain syndrome,${ }^{71}$ migraine,${ }^{72}$ and malignancies. ${ }^{73}$

According to studies in different fields, CT has multisystem binding sites including plasma membranes, bone, cultured human lymphocytes, malignant cells, and CNS neurons. The receptors for calcitonin have been found in the thalamus, periaqueductal grey, nucleus gigantocellularis, and raphe nucleus of the mouse brain where serotonergic neurons are located. These regions are associated with pain processing. ${ }^{74}$ It is likely that calcitonin exerts its primary analgesic effect through the receptor-mediating modulation of serotonergic neuronal activity during pain pathways in the CNS. ${ }^{75}$

Endorphin-mediated mechanisms were also proposed to explain the CNS mechanisms of calcitonin's analgesic action. ${ }^{76}$ However, further studies are required to confirm the connection between these two theories. Both in vitro and in vivo data using calcitonin showed that it inhibits the synthesis of pain-producing factors such as prostaglandins and cytokines. This might be a peripheral mechanism of the analgesic effect of calcitonin other than its CNS effects. Additional research will further expand our understanding of calcitonin and its antinociceptive activity. In the future calcitonin may emerge as additional analgesic used along NSAIDs and opioids.

\section{OTHER HORMONES INVOLVED IN PAIN}

Insulin and insulin-like growth factors (IGFs) are required for vital neuronal functions. Diabetes, metabolic syndrome, and other conditions characterized by absolute or functional deficiencies of insulin or IGF-1 may also present neuronal and vascular complications. Insulin resistance arises in migraine, ${ }^{77}$ painful peripheral diabetic neuropathy, and musculoskeletal pain. ${ }^{78}$ Acute pain can also induce insulin resistance. ${ }^{79}$ Determination of the molecular mechanisms remains a challenging goal. ${ }^{80}$ Maintenance of normal glucose metabolism may provide acute pain relief and reduce pain chronicity.

Prolactin abnormalities have been observed in autoimmune disease, ${ }^{81}$ cluster headache, ${ }^{82}$ and migraine. ${ }^{83}$ Although trials have been designed to test the use of prolactin antagonists as analgesics, further evidence of effectiveness is required.

An 18-month multicenter placebo-controlled trial conducted by Cuatrecasas et al demonstrated the effectiveness of growth hormone as an adjunctive therapy for patients with myalgia in reducing pain with sustained action over time. ${ }^{84}$ Further studies are required to determine the analgesic effect of growth hormone at the molecular level. The effectiveness of growth hormone for treating other chronic pain syndromes also necessitates further investigation.

In addition, there is a lack of conclusive evidence that somatomedin, somatostatin, histamine, vasopressin, and other hormones are linked to pain. Again, more clinical studies and basic research are warranted to test the connection of these hormones to pain.

\section{CONCLUSION}

The IASP describes pain as an unpleasant sensory, affective, and cognitive experience that is associated with actual or potential tissue damage. However, the feeling of pain is subjective and personal, unique 
and multidimensional. Sometimes, the pain a person experiences may be disproportionate to the nature and extent of tissue damage, injury or its pathology. Thus, we need a more comprehensive explanation of its generation, transmission, and processing and its pathological amplification in disease states. The hormone system may be essential to understanding this process as it can affect the human body as a whole and interact efficiently with other systems.

Modern pain neuroscience has classified pain as peripheral neuropathic pain, nociceptive pain, and central sensitization. Hormones may play different roles in different types of chronic pain. Hormone dysregulation is a component of chronic pain syndromes, but there is not yet clear evidence indicating whether these are correlated with each other or are causative. Addressing this question will guide future clinical application. Hormones could serve as important biomarkers of chronic pain syndromes during the onset or maintenance phases or may be a future therapeutic target for disease treatment. Research into the possible involvement of multiple hormones in the etiology of both chronic pain and related disorders may help us understand the links between different disease states while potentially pointing to novel strategies for the development of pharmacotherapies.

\section{FUNDING}

There was no outside funding provided for this review.

\section{CONFLICT OF INTEREST}

The authors do not have any conflict of interest.

\section{REFERENCES}

1. Nijs J, Torres-Cueco R, van Wilgen CP, et al, 2014 Applying modern pain neuroscience in clinical practice: criteria for the classification of central sensitization pain. Pain Physician 17: 447-457.

2. Smart KM, Blake C, Staines A, Thacker M, Doody C, 2012 Mechanisms-based classifications of musculoskeletal pain: part 2 of 3: symptoms and signs of peripheral neuropathic pain in patients with low back (+/- leg) pain. Man Ther 17: 345-351.

3. Woolf CJ, 2011 Central sensitization: implications for the diagnosis and treatment of pain. Pain 152:Suppl 3: $2-15$.
4. Mains RE, Eipper BA, Ling N, 1977 Common precursor to corticotropins and endorphins. Proc Natl Acad Sci USA 74: 3014-3018.

5. Roberts JL, Herbert E, 1977 Characterization of a common precursor to corticotropin and beta-lipotropin: cell-free synthesis of the precursor and identification of corticotropin peptides in the molecule. Proc Natl Acad Sci USA 74: 4826-4830.

6. Loh HH, Tseng LF, Wei E, Li CH, 1976 beta-endorphin is a potent analgesic agent. Proc Natl Acad Sci USA 73: 2895-2898.

7. Hartwig AC, 1991 Peripheral beta-endorphin and pain modulation. Anesth Prog 38: 75-78.

8. Mousa SA, Shakibaei M, Sitte N, Schafer M, Stein C, 2004 Subcellular pathways of beta-endorphin synthesis, processing, and release from immunocytes in inflammatory pain. Endocrinology 145: 1331-1341.

9. Mastorakos G, Pavlatou MG, Mizamtsidi M, 2006 The hypothalamic-pituitary-adrenal and the hypothalamicpituitary-gonadal axes interplay. Pediatr Endocrinol Rev 3:Suppl 1: 172-181.

10. Makman MH, Bilfinger TV, Stefano GB, 1995 Human granulocytes contain an opiate alkaloid-selective receptor mediating inhibition of cytokine-induced activation and chemotaxis. J Immunol 154: 1323-1330.

11. Cabot PJ, Carter L, Gaiddon C, et al, 1997 Immune cell-derived beta-endorphin. Production, release, and control of inflammatory pain in rats. J Clin Invest 100: 142-148.

12. Simpkins CO, Dickey CA, Fink MP, 1984 Human neutrophil migration is enhanced by beta-endorphin. Life Sci 34: 2251-2255.

13. Kapitzke D, Vetter I, Cabot PJ, 2005 Endogenous opioid analgesia in peripheral tissues and the clinical implications for pain control. Ther Clin Risk Manag 1: 279-297.

14. Levine JD, Gordon NC, Fields HL, 1979 Naloxone dose dependently produces analgesia and hyperalgesia in postoperative pain. Nature 278: 740-741.

15. Corder G, Doolen S, Donahue RR, et al, 2013 Constitutive $\mu$-opioid receptor activity leads to long-term endogenous analgesia and dependence. Science 341: 1394-1399.

16. Pereira MP, Donahue RR, Dahl JB, Werner M, Taylor BK, Werner MU, 2015 Endogenous Opioid-Masked Latent Pain Sensitization: Studies from Mouse to $\mathrm{Hu}-$ man. PLoS One 10: e0134441.

17. Lee M, Silverman SM, Hansen H, Patel VB, Manchikanti L, 2011 A comprehensive review of opioid-induced hyperalgesia. Pain Physician 14: 145-161.

18. Qin ZL, Yang LQ, Li N, et al, 2016 Clinical study of cerebrospinal fluid neuropeptides in patients with primary trigeminal neuralgia. Clin Neurol Neurosurg 143: 111-115.

19. Jadric R, Kiseljakovic E, Hasic S, Winterhalter-Jadric M, 2007 Beta-endorphins as possible markers for thera- 
peutic drug monitoring. Bosn J Basic Med Sci 7: 11-14.

20. Bruehl S, Burns JW, Chung OY, Chont M, 2012 What do plasma beta-endorphin levels reveal about endogenous opioid analgesic function? Eur J Pain 16: 370-380.

21. Bruehl S, Burns JW, Gupta R, et al, 2016 Do Resting Plasma Beta-Endorphin Levels Predict Responses to Opioid Analgesics? Clin J Pain [Epub ahead of print].

22. Griep EN, Boersma JW, Lentjes EG, Prins AP, van der Korst JK, de Kloet ER, 1998 Function of the hypothalamic-pituitary-adrenal axis in patients with fibromyalgia and low back pain. J Rheumatol 25: 1374-1381.

23. Cleare AJ, 2004 The HPA axis and the genesis of chronic fatigue syndrome. Trends Endocrinol Metab 15: 55-59.

24. Chang L, Sundaresh S, Elliott J, et al, 2009 Dysregulation of the hypothalamic-pituitary-adrenal (HPA) axis in irritable bowel syndrome. Neurogastroenterol Motil 21: 149-159.

25. Blackburn-Munro G, Blackburn-Munro RE, 2001 Chronic pain, chronic stress and depression: coincidence or consequence? J Neuroendocrinol 13: 1009-1023.

26. Ulrich-Lai YM, Xie W, Meij JT, Dolgas CM, Yu L, Herman JP, 2006 Limbic and HPA axis function in an animal model of chronic neuropathic pain. Physiol Behav 88: 67-76.

27. Kloppenburg M, Dijkmans BA, Rasker JJ, 1993 Effect of therapy for thyroid dysfunction on musculoskeletal symptoms. Clinical Rheumatol 12: 341-345.

28. Hagen K, Bjoro T, Zwart JA, Vatten L, Stovner LJ, Bovim G, 2001 Low headache prevalence amongst women with high TSH values. Eur J Neurol 8: 693-699.

29. Neeck G, Crofford LJ, 2000 Neuroendocrine perturbations in fibromyalgia and chronic fatigue syndrome. Rheum Dis Clin North Am 26: 989-1002.

30. Alves IG, da Cruz KM, Mota CM, et al, 2013 Experimental hypothyroidism during pregnancy affects nociception and locomotor performance of offspring in rats. Eur J Pain 17: 1291-1298.

31. Dussault JH, Ruel J, 1987 Thyroid hormones and brain development. Annu Rev Physiol 49: 321-334.

32. Bernal J, 2002 Action of thyroid hormone in brain. J Endocrinol Invest 25: 268-288.

33. Aloisi AM, Vodo S, Buonocore M, 2013 Pain and thyroid hormones. Neurol Sci 34: 1501-1508.

34. Narita M, Niikura K, Nanjo-Niikura K, et al, 2011 Sleep disturbances in a neuropathic pain-like condition in the mouse are associated with altered GABAergic transmission in the cingulate cortex. Pain 152: 13581372.

35. Dickenson AH, 1996 Balances between excitatory and inhibitory events in the spinal cord and chronic pain. Prog Brain Res 110: 225-231.

36. Wiens SC, Trudeau VL, 2006 Thyroid hormone and gamma-aminobutyric acid (GABA) interactions in neuroendocrine systems. Comp Bioch Physiol A Mol Integr Physiol 144: 332-344.
37. McCarberg BH, 2012 Clinical overview of fibromyalgia. Am J Ther 19: 357-368.

38. Lipton RB, Stewart WF, Scher AI, 2001 Epidemiology and economic impact of migraine. Curr Med Res Opin 17:Suppl 1: 4-12.

39. Flier SN, Rose S, 2006 Is functional dyspepsia of particular concern in women? A review of gender differences in epidemiology, pathophysiologic mechanisms, clinical presentation, and management. Am J Gastroenderol 101: 12 Suppl: 644-653.

40. Walker EA, Gelfand AN, Gelfand MD, Green C, Katon WJ, Chronic pelvic pain and gynecological symptoms in women with irritable bowel syndrome. J Psychosom Obstet Gynaecol 17: 39-46.

41. Dinos S, Khoshaba B, Ashby D, et al, 2009 A systematic review of chronic fatigue, its syndromes and ethnicity: prevalence, severity, co-morbidity and coping. Int $\mathrm{J}$ Epidemiol 38: 1554-1570.

42. Grigoriadis S, Robinson GE, 2007 Gender issues in depression. Ann Clin Psychiatry 19: 247-255.

43. Meleine M, Matricon J, 2014 Gender-related differences in irritable bowel syndrome: potential mechanisms of sex hormones. World J Gastroenterol 20: 6725-6743.

44. Iacovides S, Avidon I, Baker FC, 2015 Women with dysmenorrhoea are hypersensitive to experimentally induced forearm ischaemia during painful menstruation and during the pain-free follicular phase. Eur J Pain 19: 797-804.

45. Lee CW, Ho IK, 2013 Sex differences in opioid analgesia and addiction: interactions among opioid receptors and estrogen receptors. Mol Pain 9: 45.

46. Vincent K, Warnaby C, Stagg CJ, Moore J, Kennedy S, Tracey I, 2013 Brain imaging reveals that engagement of descending inhibitory pain pathways in healthy women in a low endogenous estradiol state varies with testosterone. Pain 154: 515-524.

47. Aloisi AM, Bachiocco V, Costantino A, et al, 2007 Cross-sex hormone administration changes pain in transsexual women and men. Pain 132: Suppl 1: 60-67.

48. Bartley EJ, Fillingim RB, 2013 Sex differences in pain: a brief review of clinical and experimental findings. Br J Anaesth 111: 52-58.

49. Veldhuijzen DS, Keaser ML, Traub DS, Zhuo J, Gullapalli RP, Greenspan JD, 2013 The role of circulating sex hormones in menstrual cycle-dependent modulation of pain-related brain activation. Pain 154: 548-559.

50. White HD, Robinson TD, 2015 A novel use for testosterone to treat central sensitization of chronic pain in fibromyalgia patients. Int Immunopharmacol 27: 244-248.

51. Lakin ML, Miller CH, Stott ML, Winters WD, 1981 Involvement of the pineal gland and melatonin in murine analgesia. Life Sci 29: 2543-2551.

52. Williams LM, Hannah LT, Hastings MH, Maywood ES, 1995 Melatonin receptors in the rat brain and pituitary. J Pineal Res 19: 173-177. 
53. Ambriz-Tututi M, Rocha-Gonzalez HI, Cruz SL, Granados-Soto V, 2009 Melatonin: a hormone that modulates pain. Life Sci 84: 489-498.

54. Jeong JH, Choi KB, Yi BC, et al, 2000 Effects of extremely low frequency magnetic fields on pain thresholds in mice: roles of melatonin and opioids. J Auton Pharmacol 20: 259-264.

55. Shavali S, Ho B, Govitrapong P, et al, 2005 Melatonin exerts its analgesic actions not by binding to opioid receptor subtypes but by increasing the release of betaendorphin an endogenous opioid. Brain Ress Bull 64: 471-479.

56. Song L, Wu C, Zuo Y, 2015 Melatonin prevents morphine-induced hyperalgesia and tolerance in rats: role of protein kinase $\mathrm{C}$ and $\mathrm{N}$-methyl-D-aspartate receptors. BMC Anesthesiol 15: 12.

57. Mauriz JL, Collado PS, Veneroso C, Reiter RJ, GonzalezGallego J, 2013 A review of the molecular aspects of melatonin's anti-inflammatory actions: recent insights and new perspectives. J Pineal Res 54: 1-14.

58. Ulugol A, Dokmeci D, Guray G, Sapolyo N, Ozyigit F, Tamer M, 2006 Antihyperalgesic, but not antiallodynic, effect of melatonin in nerve-injured neuropathic mice: Possible involvements of the L-arginine-NO pathway and opioid system. Life Sci 78: 1592-1597.

59. Schomberg D, Miranpuri G, Duellman T, Crowell A, Vemuganti R, Resnick D, 2015 Spinal cord injury induced neuropathic pain: Molecular targets and therapeutic approaches. Metab Brain Dis 30: 645-658.

60. Deng YK, Ding JF, Liu J, Yang YY, 2015 Analgesic effects of melatonin on post-herpetic neuralgia. Int $\mathrm{J}$ Clin Exp Med 8: 5004-5009.

61. Vogler B, Rapoport AM, Tepper SJ, Sheftell F, Bigal ME, 2006 Role of melatonin in the pathophysiology of migraine: implications for treatment. CNS Drugs 20: 343-350.

62. Yamamoto H, Tang H, 1998 Effects of 2-amino-7-phosphonohepatanoic acid, melatonin or NG-nitro-L-arginine on cyanide or N-methyl-D-aspartate-induced neurotoxicity in rat cortical cells. Toxicol Lett 94: 13-18.

63. Wikner J, Hirsch U, Wetterberg L, Rojdmark S, 1998 Fibromyalgia--a syndrome associated with decreased nocturnal melatonin secretion. Clin Endocrinol (Oxf) 49: 179-183.

64. Knook L, Kavelaars A, Sinnema G, Kuis W, Heijnen CJ, 2000 High nocturnal melatonin in adolescents with chronic fatigue syndrome. J Clin Endocrinol Metab 85: 3690-3692.

65. Radwan P, Skrzydlo-Radomanska B, Radwan-Kwiatek K, Burak-Czapiuk B, Strzemecka J, 2009 Is melatonin involved in the irritable bowel syndrome? J Physiol Pharmacol 60: Suppl 3: 67-70.

66. Copp DH, Cameron EC, 1961 Demonstration of a hypocalcemic factor (calcitonin) in commercial parathyroid extract. Science 134: 2038.

67. Austin LA, Heath H $3^{\text {rd }}, 1981$ Calcitonin: physiology and pathophysiology. N Engl J Med 304: 269-278.

68. Knopp JA, Diner BM, Blitz M, Lyritis GP, Rowe BH, 2005 Calcitonin for treating acute pain of osteoporotic vertebral compression fractures: a systematic review of randomized, controlled trials. Osteoporos Int 16: 1281-1290.

69. Jaeger H, Maier C, 1992 Calcitonin in phantom limb pain: a double-blind study. Pain 48: 21-27.

70. Zieleniewski W, 1990 Calcitonin nasal spray for painful diabetic neuropathy. Lancet 336: 449.

71. Appelboom T, 2002 Calcitonin in reflex sympathetic dystrophy syndrome and other painful conditions. Bone 30:Suppl 5: 84-86.

72. Gennari C, Chierichetti MS, Gonnelli S, Vibelli C, Montagnani M, Piolini M, 1986 Migraine prophylaxis with salmon calcitonin: a cross-over double-blind, placebo-controlled study. Headache 26: 13-16.

73. Martinez-Zapata MJ, Roque M, Alonso-Coello P, Catala E, 2006 Calcitonin for metastatic bone pain. Cochrane Database Syst Rev 19: CD003223.

74. Nakamoto H, Soeda Y, Takami S, Minami M, Satoh M, 2000 Localization of calcitonin receptor mRNA in the mouse brain: coexistence with serotonin transporter mRNA. Brain Res Mol Brain Res 76: 93-102.

75. Colado MI, Ormazabal MJ, Goicoechea C, Lopez F, Alfaro MJ, Martin MI, 1994 Involvement of central serotonergic pathways in analgesia elicited by salmon calcitonin in the mouse. Eur J Pharmacol 252: 291-297.

76. Laurian L, Oberman Z, Graf E, Gilad S, Hoerer E, Simantov R, 1986 Calcitonin induced increase in ACTH, beta-endorphin and cortisol secretion. Horm Metab Res 18: 268-271.

77. Bhoi SK, Kalita J, Misra UK, 2012 Metabolic syndrome and insulin resistance in migraine. J Headache Pain 13: 321-326.

78. Seaman DR, 2013 Body mass index and musculoskeletal pain: is there a connection? Chiropr Man Therap 21: 15.

79. Greisen J, Juhl CB, Grofte T, Vilstrup H, Jensen TS, Schmitz O, 2001 Acute pain induces insulin resistance in humans. Anesthesiology 95: 578-584.

80. Chen WN, Lee CH, Lin SH, et al, 2014 Roles of ASIC3, TRPV1, and NaV1.8 in the transition from acute to chronic pain in a mouse model of fibromyalgia. Mol Pain 10: 40.

81. Berczi I, 1993 Prolactin, pregnancy and autoimmune disease. J Rheumatol 20: 1095-1100.

82. Polleri A, Nappi G, Murialdo G, Bono G, Martignoni E, Savoldi F, 1982 Changes in the 24-hour prolactin pattern in cluster headache. Cephalalgia 2: 1-7.

83. Cavestro C, Rosatello A, Marino MP, Micca G, Asteggiano G, 2006 High prolactin levels as a worsening factor for migraine. J Headache Pain 7: 83-89.

84. Cuatrecasas G, Alegre C, Casanueva FF, 2014 GH/IGF1 axis disturbances in the fibromyalgia syndrome: is there a rationale for GH treatment? Pituitary 17: 277-283. 